\title{
JMSR
}

Journal of Medical

and Scientific Research

\section{Clinicopathological spectrum of patients with lupus nephritis in a tertiary care hospital

\author{
Harika Venishetty ${ }^{1}$, Sujatha Poduval $\mathrm{K}^{1}$, Satish Rao $\mathrm{I}^{1}$, and Reddy $\mathrm{VS}^{2}$
}

\author{
${ }^{1}$ Department of Pathology, Krishna Institute of Medical Sciences, Minister Road, Secunderabad-500003, Telangana, India \\ ${ }^{2}$ Department of Nephrology, Krishna Institute of Medical Sciences, Minister Road, Secunderabad-500003, Telangana, India
}

\begin{abstract}
Aim: The aim is to determine the distribution of different classes of lupus nephritis based on renal biopsy and to correlate it with serum creatinine and proteinuria.

Objectives: To study the prevalence of different classes of systemic lupus erythematosus (SLE) using the International Society of Nephrology/Renal Pathology Society (ISN/RPS) 2003 classification in our facility, and to determine the correlation between the histopathological features of different classes of lupus nephritis and the clinical and laboratory parameters.

Material and methods: Renal biopsy specimens with a clinical diagnosis of SLE by ARA criteria in a period of 3 years received in the laboratory were included in the study and were classified according ISN/RPS 2003 classification. The clinical and laboratory data were obtained from patient files.

Results: Out of 40 patients, 35 (88\%) were females and 5 (12\%) were male patients. Mean age was $32.7 \pm 10.7$ years. Majority of patients belong to class IV (53\%) followed by class III (22\%).

Conclusion: In this study the commonest class of International Society of Nephrology (ISN)/Renal Pathology Society (RPS) classification is class IV and there is significant correlation between $24 \mathrm{~h}$ proteinuria with ISN/ RPS classes.
\end{abstract}

Keywords: Systemic lupus erythematosus; lupus nephritis; nephritic syndrome; autoimmune

*Corresponding author: Dr. Sujatha Poduval K, Department of Pathology, Krishna Institute of Medical Sciences, Minister Road, Secunderabad-500003, Telangana, India. Email: radhakishore. veni@gmail.com

Received 21 January 2019; Revised 7 March 2019; Accepted 18 March 2019; Published 26 March 2019

Citation: Venishetty H, Poduval KS, Satishrao I, Reddy VS. Clinicopathological spectrum of patients with lupus nephritis in a tertiary care hospital. J Med Sci Res. 2019; 7(2):36-42. DOI: http://dx.doi.org/10.17727/JMSR.2019/7-8

Copyright: (C) 2019 Venishetty H et al. Published by KIMS Foundation and Research Center. This is an open-access article distributed under the terms of the Creative Commons Attribution License, which permits unrestricted use, distribution, and reproduction in any medium, provided the original author and source are credited.

\section{Introduction}

Systemic lupus erythematosus (SLE) is a chronic relapsing multisystem autoimmune disease and is characterized by presence of autoantibodies directed against nuclear antigens affecting multiple organs which include kidney, joints, skin, brain, heart, serosa, lungs and gastrointestinal tract.

Lupus nephritis (LN) is immune complex disease that occurs in patients who meet American College of Rheumatology criteria for diagnosis of SLE [1]. Lupus nephritis is characterized by inflammatory damage to nephrons during the SLE flare with distinct clinical features involving nephrons and 
thus showing variable histological findings. Thus, giving different lesions at a particular point of time.

Clinical spectrum of lupus nephritis ranges from mild proteinuria to rapidly progressive renal failure [2]. Around $60 \%$ of adults and $80 \%$ of children with SLE develop LN [3]. End-stage renal disease (ESRD) is the terminal event in lupus nephritis. Patients with LN have a 26- fold increased risk of early death in comparison with age related population.

Renal involvement is common in SLE [2]. The American College of Rheumatology recommends to do renal biopsy in SLE patients if they have one of the following: $24 \mathrm{~h}$ proteinuria $>1 \mathrm{~g}$, or abnormal renal function or $24 \mathrm{~h}$ proteinuria $>0.5 \mathrm{~g}$ along with either active sediments [2]. The typical feature in lupus nephritis is immune complex deposition, which shows a "full house" picture under immunofluorescence observation. The occurrence of the spectrum of renal disease in SLE patients varies from $35-90 \%$, reflecting the great diversity in clinical manifestations and disease severity of LN [4].

Kidney biopsy is the main-stay for the diagnosis of LN. Material obtained by renal biopsy is evaluated by light microscope, immunofluorescence and electron microscopy where available. In many cases renal biopsy is instrumental in establishing diagnosis of $\operatorname{LN}[5,6]$. Most patients of $L N$ can be diagnosed with study of light microscope, immunofluorescence with the aid of special stains. The morphological expression can vary considerably, among patients or within individuals over time, which is related to the location, quantity and pro-inflammatory properties of immune deposits [6].

The renal biopsy is performed not only for diagnostic purpose but also for the therapeutic and prognostic purpose [7]. The factors affecting outcome of disease are controversial with worse prognosis in male sex, black race, onset before puberty, persistent hypertension, impaired renal function, nephrotic syndrome, anemia, class IV nephritis and increased histological activity index scores [8]. However, the World Health Organization classification and National Institutes of Health (NIH) system of activity indices and chronicity indices do not lay emphasis of renal vasculature [9].

Not many studies are there with respect to the frequencies of histological classification of LN classes in southern part of India. Therefore, we attempt to look at the frequency of various classes of $L N$ in patients in tertiary hospital in southern India.

\section{Methodology}

This is a retrospective and prospective observational study conducted in Department of Pathology, Krishna Institute of Medical Sciences Hospital over a period of 37 months from January 2015 to February 2018. A total of 40 patients were included in the study who fulfilled the inclusion and exclusion criteria and consent was obtained from all the patients.

\section{Inclusion criteria}

The patients who fulfilled the revised American College of Rheumatology (ACR) criteria for systemic lupus erythematosus.

\section{Exclusion criteria}

Patients who are not satisfying criteria of systemic lupus erythematosus. After proper history and consent histologically confirmed patients of LN (classified based on ISN/RPS 2003 classification) were studied and correlated with laboratory parameters. Ethical clearance from the institutional ethical committee was obtained.

Data were collected as per the case report form. Two cores received, one in normal saline and one in formalin solution. The tissue was placed in 10\% formalin for light microscopic (LM) examination and in saline for immunofluorescence (IF) studies. For LM, multiple step serials from renal core were stained and studied using hematoxylin and eosin, periodic acid-Schiff, Masson's trichrome stain, and Jones silver methanamine stain. For IF, the biopsy specimens were washed in phosphate-buffered saline (PBS) thrice followed by embedding the tissue for frozen section in optimum cutting temperature medium. Once the tissue was frozen, 2-3 micron thin sections were cut. The slides were then stained with fluoroscein-isothiocynate (FITC) labeled anti-human antibodies of IgG, IgA, IgM, C3, C1q, kappa, and lambda light chains. The slides were then incubated for an hour at $37^{\circ} \mathrm{C}$. After incubation the slides were again washed thrice with PBS, mounted with glycerin and viewed under immunofluorescent microscope Olympus.

The whole data was entered in Microsoft excel master sheet and analyzed using statistical Windostat 9.3 software. As the data was qualitative 
and quantitative, data was subjected to t-test and ANOVA test used to assess the association between these parameters. A value of $p<0.05$ was taken as significant and $<0.01$ as highly significant; whereas, p $>0.05$ was taken as non-significant.

\section{Results}

Age of the patients ranged from 15 - 61 years. The mean age was $32.7 \pm 10.7$ years. Minimum age was 15 years and maximum age was 61 years. Majority was females 35/40 and males were 5/40 cases, M : $\mathrm{F}$ ratio was 1:7.

\section{Lupus nephritis class distribution}

class IV constituted 24 (53\%) patients followed by 9 patients $(22 \%)$ in class III, $4(10 \%)$ patients each for class II and class V and 2 (5\%) patients of class I (Table 1). In our series, there was no class VI patient.

\section{Anti double stranded DNA}

Anti double stranded DNA was positive for 34 (85\%) patients and negative for $6(15 \%)$ patients.

Table1: LN class distribution.

\begin{tabular}{|c|c|c|c|c|c|}
\hline Class & Renal lesion & No. of patients & Frequency & $\begin{array}{c}\text { Percentage } \\
(\%)\end{array}$ & Total \\
\hline I & Normal glomeruli & 2 & 2 & 5 & 2 \\
\hline \multirow{3}{*}{ II } & Pure mesangial GN & & 4 & 10 & \multirow{3}{*}{4} \\
\hline & Mild hyper cellularity & 2 & & & \\
\hline & Moderate hypercellularity & 2 & & & \\
\hline \multirow{3}{*}{ III } & Focal and segmental GN & & 9 & 22 & \multirow{3}{*}{9} \\
\hline & Active necrotizing lesions & 6 & & & \\
\hline & Active and sclerosing lesions & 3 & & & \\
\hline \multirow{2}{*}{ IV } & Diffuse proliferative GN & & 21 & 53 & \multirow{2}{*}{21} \\
\hline & Necrotizing lesion \&/ with crescents & 21 & & & \\
\hline \multirow{3}{*}{ V } & Diffuse membranous GN & & 4 & 10 & \multirow{3}{*}{4} \\
\hline & Pure membranous lesions & 3 & & & \\
\hline & Associated with class III & 1 & & & \\
\hline VI & Advanced sclerosing GN & 0 & 0 & 0 & 0 \\
\hline Total & & & & & 40 \\
\hline
\end{tabular}

The mean $24 \mathrm{~h}$ proteinuria was highest for class $\mathrm{V}$ $(6.74 \pm 3.96)$ followed by class IV $(2.067 \pm 1.075)$, class III $(1.526 \pm 1.036)$ and least proteinuria observed in class II $(0.673 \pm 0.841)$ and class I $(0.966 \pm 0.81)$ indicating that higher the class higher the protein excretion. This study showed significant association of $24 \mathrm{~h}$ proteinuria with ISN/RPS classification system of LN ( $p=0.0001)$ as mentioned in Table 2 .

Mean serum creatinine was higher in class IV $(1.88 \pm 1.27)$ than class V and class III as mentioned in the Table 2. No correlation of serum creatinine with LN classes. However, the number of cases of class $\mathrm{V}$ is limited.
Significant correlation is seen between A/I and C/I of class IV with serum creatinine and $24 \mathrm{~h}$ proteinuria. Significant correlation seen between only A/I of class III with serum creatinine and $24 \mathrm{~h}$ proteinuria.

No significant correlation is seen between C/I of class III with serum creatinine and $24 \mathrm{~h}$ proteinuria as mentioned in Table 4.

\section{Immunofluorescence pattern}

Twenty four (60\%) biopsies showed full house staining with positivity for immunoglobulin's IgG, IgA, IgM, complements C3c, $\mathrm{C}_{1} \mathrm{q}$, Kappa and Lambda, $15(37 \%)$ patients did not show full house staining 
Table 2: Association between biochemical parameters and ISN/RPS classification system.

\begin{tabular}{|lcccccc|}
\hline & $\begin{array}{c}\text { Class I } \\
n=2\end{array}$ & $\begin{array}{c}\text { Class II } \\
n=4\end{array}$ & $\begin{array}{c}\text { Class III } \\
n=9\end{array}$ & $\begin{array}{c}\text { Class IV } \\
n=21\end{array}$ & $\begin{array}{c}\text { Class V } \\
n=4\end{array}$ & $p$-value \\
\hline $\begin{array}{l}\text { 24h proteinuria } \\
\text { (gm/day) }\end{array}$ & $0.966 \pm 0.81$ & $0.673 \pm 0.841$ & $1.526 \pm 1.036$ & $2.067 \pm 1.075$ & $6.74 \pm 3.96$ & 0.0001 \\
$\begin{array}{l}\text { Creatinine } \\
(\mathrm{mg} / \mathrm{dl})\end{array}$ & $0.57 \pm 0.007$ & $0.9225 \pm 0.35$ & $1.077 \pm 0.43$ & $1.88 \pm 1.27$ & $1.42 \pm 0.838$ & NS $(0.137)$ \\
$\begin{array}{l}\text { Hemoglobin \% } \\
\text { GFR }\end{array}$ & $12.05 \pm 0.77$ & $10.825 \pm 1.147$ & $10.78 \pm 2.23$ & $10.73 \pm 1.80$ & $8.05 \pm 0.939$ & NS (0.07) \\
$\begin{array}{l}\text { Anti ds DNA } \\
\text { levels }\end{array}$ & $2.845 \pm 2.76$ & $1.705 \pm 2.66$ & $5.94 \pm 4.23$ & $5.78 \pm 2.02$ & $5.05 \pm 3.27$ & NS (0.09) \\
\hline
\end{tabular}

and one(3\%) patient of class I showed negative for all (Table 4). Out of forty patients, 15 patients showed non full house picture (Figures 1 to 6 ).

Table 3: Correlation of activity and chronicity indices with serum creatinine and $24 \mathrm{~h}$ proteinuria of class III \& IV.

\begin{tabular}{|lc|}
\hline Variables correlated & $P$ value \\
\hline Class III A/I X Serum creatinine & 0.0130 \\
Class III A/I X 24h proteinuria & 0.0439 \\
Class IV A/I X Serum creatinine & 0.0001 \\
Class IV A/I X 24h proteinuria & 0.0001 \\
Class III C/I X Serum creatinine & 0.678 \\
Class III C/I X 24h proteinuria & 0.6131 \\
Class IV C/I X Serum creatinine & 0.0041 \\
Class IV C/I X 24h proteinuria & 0.0003 \\
\hline
\end{tabular}

Table 4: Showing distribution of immunoglobulin's, complements and light chains.

\begin{tabular}{|lcc|}
\hline $\begin{array}{l}\text { Immuno- } \\
\text { fluorescence }\end{array}$ & $\begin{array}{c}\text { Positive patients } \\
(\mathrm{n} / 15)\end{array}$ & $\begin{array}{c}\text { Percentage } \\
(\%)\end{array}$ \\
\hline IgG & 12 & 80 \\
IgA & 5 & 35.71 \\
IgM & 3 & 21.42 \\
C3c & 11 & 78.57 \\
C1q & 12 & 80 \\
Kappa & 11 & 78.57 \\
Lambda & 10 & 71.42 \\
\hline
\end{tabular}
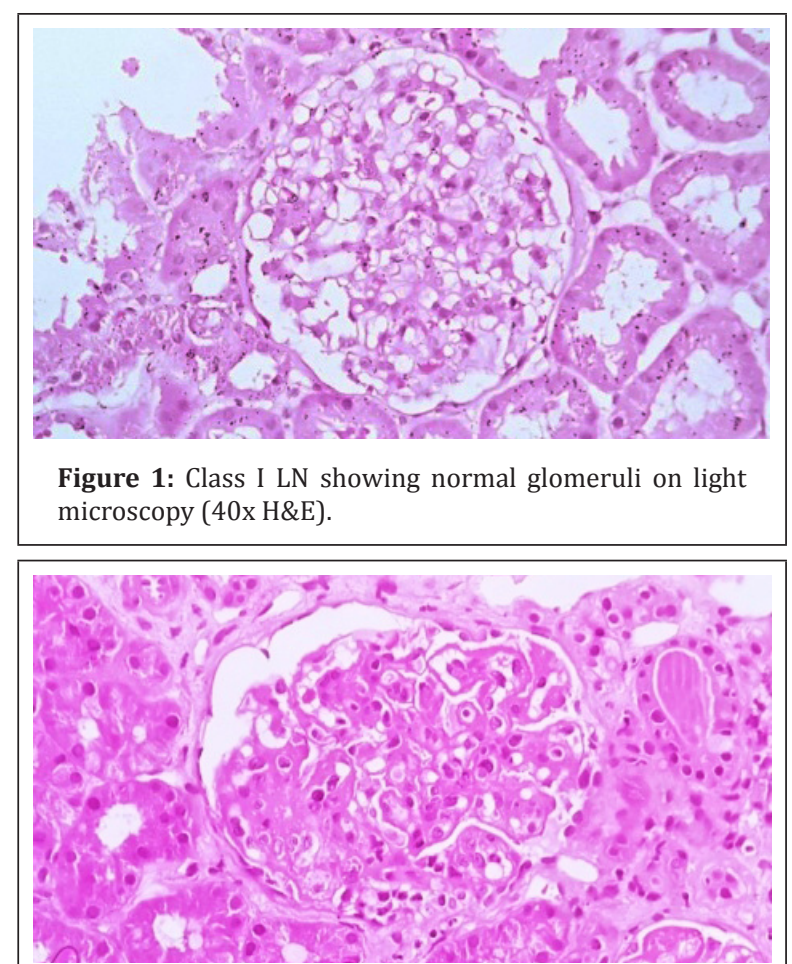

Figure 2: Class II LN showing mesangial hypercellularity (40x H\&E).

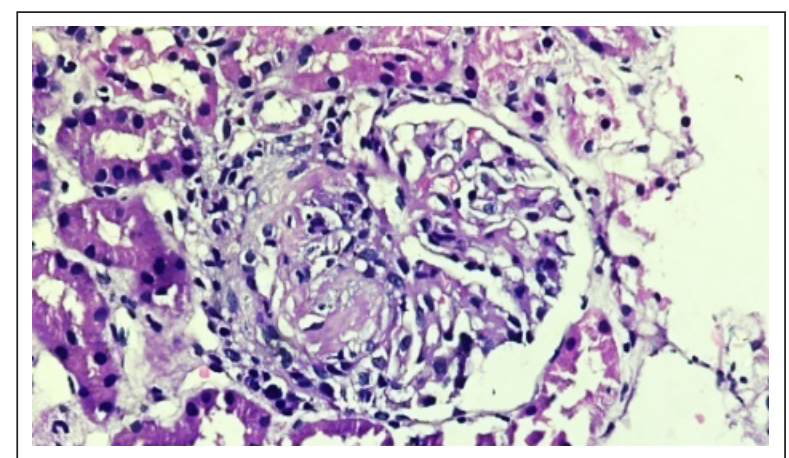

Figure 3: Class III LN showing focal lupus nephritis (40x H\&E). 


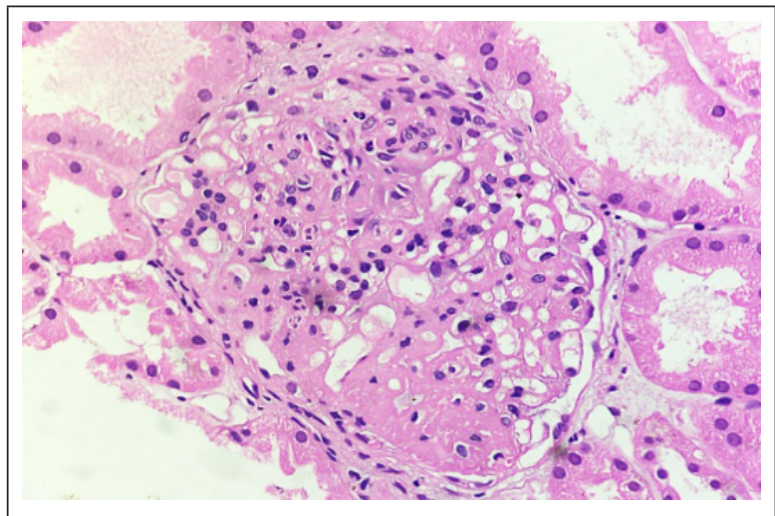

Figure 4: Class IV LN showing wire loop deposits and hyaline thrombi (40X H\&E).

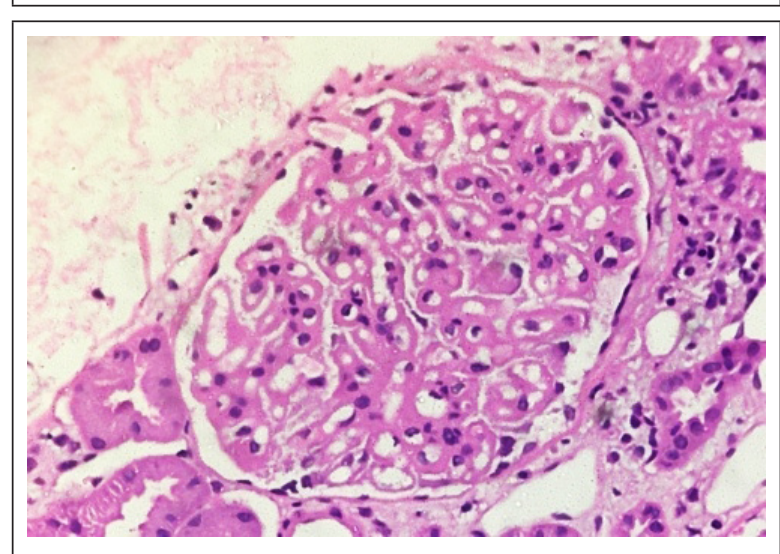

Figure 5: Class V LN showing diffuse membranous thickening of glomerular capillary walls (40xH\&E).

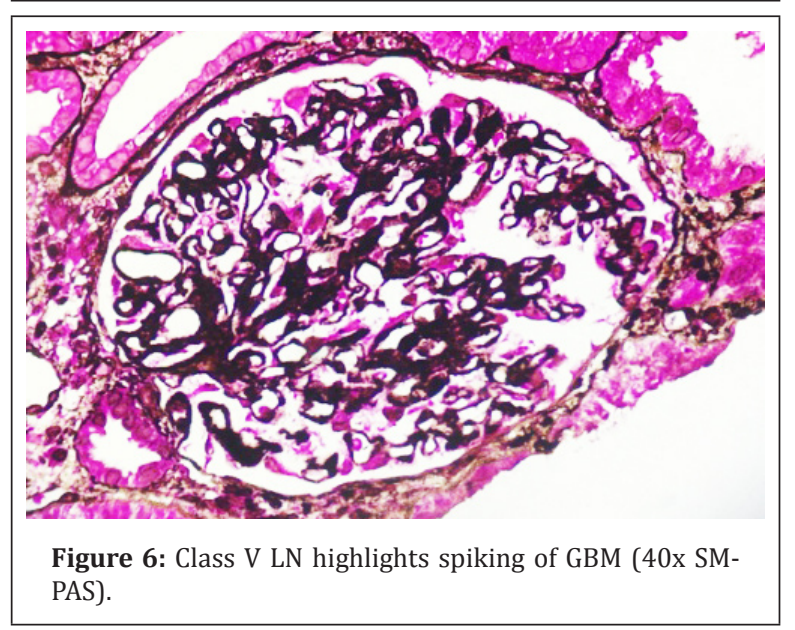

\section{Discussion}

Forty patients who fulfilled the ACR criteria of SLE and underwent renal biopsy were included in the study conducted at Department of Pathology, KIMS Hospital, Secunderabad.

The age of patients ranged from $15-61$ years. Mean age of the patients was $32.7 \pm 10.7$ years similar to
Nasri et al. [3] and Okpechi et al. [10] more than $31 \pm 4.2$ years as of Ismail et al [11], Merza et al [12]. Majority of the patients in this study were in the $4^{\text {th }}$ decade of life followed by $3^{\text {rd }}$ and $2^{\text {nd }}$ decades respectively as observed in study by Anureet et al. [13].

The most common class was class IV (53\%) followed by class III (22\%), V (10\%), II (10\%) and I (5\%) in descending order, similar to many other studies $[2$, $5,11,13,14,16]$. No case of class VI observed in our study.

There was female preponderance. Out of 40 patients, $88 \%(n=35)$ were female and $12 \%(n=5)$ were male. Female to male ratio was 7:1 similar to the study $[14,15]$.

The mean serum creatinine was $1.497 \pm 1.06$ across all classes of LN. Patients of class I had a mean serum creatinine of $0.575 \pm 0.007$, class II had mean serum creatinine of $0.9225 \pm 0.350$, and class III had mean serum creatinine of $1.077 \pm 0.431$ while class IV had mean serum creatinine of $1.88 \pm 1.27$, class $\mathrm{V}$ had mean serum creatinine of $1.42 \pm 0.83$. Mean serum creatinine was progressively increasing from class I to class IV similar to many other studies [2, $4,17]$, while class $V$ had a mild decrease in serum creatinine, this could be explained by the significant activity which may be seen in class IV. The mean $24 \mathrm{~h}$ proteinuria was $2.175 \pm 2.171$ across all LN classes.

Correlation between $24 \mathrm{~h}$ proteinuria and ISN/ RPS 2003 LN classes was found to be statistically significant and is in agreement with study by Panda et al. [2], and Ajeeth et al. [4].

Twenty four hour urine protein excretion of $>500$ $\mathrm{mg} /$ day was noted in $85 \%$ patients. The highest protein excretion was found in class $V(6.74 \pm 3.96)$ followed by class IV $(2.067 \pm 1.075)$. Statistical analysis showed significant association ( $p$ value= 0.0001 ) with progressive increase in proteinuria from class I to class $\mathrm{V}$.

High serum creatinine and greater degree of proteinuria indicate severe disease presentation emphasizing that early diagnosis, and prompt and aggressive treatment of $\mathrm{LN}$ to improve outcomes of LN. 
The mean activity index was high in class IV $(9.28 \pm 4.19)$ compared to class III $(3.66 \pm 2.738)$, similar to study by Anureet et al. [13], while in our study mean chronicity index was high in class III $(1.77 \pm 0.97)$ compared to class IV $(0.809 \pm 0.980)$.

High activity index suggests presence of severe active lesions in the kidney and these patients are likely to have high serum creatinine. There was significant correlation between activity index of class III with serum creatinine ( $p$ value $=0.0130$ ) and $24 \mathrm{~h}$ proteinuria ( $\mathrm{p}$ value $=0.0439$ ). There was significant correlation between activity index of class IV with serum creatinine $(\mathrm{p}$ value $=0.0001)$ and $24 \mathrm{~h}$ proteinuria ( $\mathrm{p}$ value $=0.0001$ )

Therefore, there is significant correlation of activity index of proliferative lesions (class III \& IV) with serum creatinine and $24 \mathrm{~h}$ proteinuria. Thus, immediate intervention is advised when activity index is high to arrest the progress.

In study by Nasri et al [3] they found tubular atrophy with interstitial fibrosis (chronicity index) best correlated with serum creatinine and proteinuria. However, present study there was no correlation between chronicity index of class III with serum creatinine and $24 \mathrm{~h}$ proteinuria since our cases did not show significant tubulointerstitial changes. There was a significant correlation between chronicity index of class IV with serum creatinine ( $p$ value $=0.0041)$ and $24 \mathrm{~h}$ proteinuria $(\mathrm{p}$ value $=0.0003)$ is noted.

Microscopic hematuria was significantly higher in class V (75\%) compared to class IV (71\%) unlike Bancha et al. [18] where highest microscopic hematuria was found in class IV. Microscopic hematuria is absent in class I patients. Mean GFR was $52.3 \pm 24.8$.

Hemoglobin was found to be low in class $\mathrm{V}$ $(8.05 \pm 0.939)$ followed by class IV $(10.73 \pm 1.80)$. The exact cause of anemia has to be determined by complete hematological work up which includes bone marrow study to look for drug induced marrow suppression which was not done in present study. Erythropoietin levels study is recommended as a part of workup to rule out anemia due to progressive renal failure.
ANA was found positive in all the 40 patients (100\%). Similar observation was seen in study by Ismail et al. [11]. Anti ds DNA was found positive in $85 \%$ patients, similar to studies by Ismail et al. [11] and Okpechi et al. [10].

In our study we found 24 (60\%) biopsies showing full house pattern of immunoglobulin deposition similar to observation in studies by Baqui et al [16]. One case of class I LN had no IF deposits explaining that this could be a patient of lupus podocytopathy, which is diagnosed only by EM. The most common immunoglobulin found was IgG (80\%) and C1q (80\%) similar to studies by Baqui et al [16]. The next common was C3c (78.57\%) and lambda (78.57\%).

\section{Conclusion}

The results from our study in biopsy proven cases of LN largely concur with the previously reported studies from other parts of the world. We conclude that in our study the commonest class of ISN// RPS classification is class IV and there is significant correlation between $24 \mathrm{~h}$ proteinuria with ISN/ RPS classes. This study also suggests that renal biopsies are essential for evaluation of renal status, determination of $\mathrm{LN}$ classes and management guidelines.

\section{Conflict of interest}

Authors declare no conflict of interest.

\section{References}

[1] Fogo AB, Lusco MA, Najafian B, Alpers CE. AJKD Atlas of Renal Pathology: Focal and Diffuse Lupus Nephritis (ISN/ RPS class III and IV). Am J Kidney Dis. 2017; 70(2):e9-e11.

[2] Panda SR, Kar C, Sahu PK, Rout S, Mohanty B, et al. Clinicopathological characteristics of Lupus Nephritis in eastern zone of India: A single tertiary center experience. Asian J Pharm Clin Res, 2016; 9(5):102-104

[3] Nasri H, Ahmadi A, Baradaran A, Momeni A, Nasri P, et al. Clinicopathological correlations in lupus nephritis; a single center experience. J Nephropathol. 2014; 3(3):115-120.

[4] Kumar CRA, Pothen L, Karthikeyan TM, Jayakumar KP. A clinicopathological study of 48 cases of lupus nephritis. MedPulse International Journal of Pathology. 2017; 3(1):3135.

[5] Satish S, Deka P, Shetty MS. A clinico-pathological study of lupus nephritis based on the International Society of Nephrology-Renal Pathology Society 2003 classification system. J Lab Physicians. 2017; 9(3):149-155.

[6] Kiremitci S, Ensari A. Classifying lupus nephritis: an ongoing story. Scientific World Journal. 2014; 2014:580620. 
[7] Singh U, Shevra CR, Singh RG, Prakash J, Singh S, et al. Histopathological study of lupus nephritis with special reference to nonlupus nephritis, focal segmental glomerulosclerosis, interstitial nephritis, and amyloidosis. CHRISMED J Health Res 2016; 3:15-21.

[8] Seema HS. A clinicopathological study of pediatric lupus nephritis in a tertiary hospital of Bangalore. Int J Cur Res Rev. 2015; 7(12):44-47.

[9] Wu LH, Yu F, Tan Y, Qu Z, Chen MH, et al. Inclusion of renal vascular lesions in the 2003 ISN/RPS system for classifying lupus nephritis improves renal outcome predictions. Kidney Int. 2013; 83(4):715-23.

[10] Okpechi IG, Swanepoel CR, Tiffin N, Duffield M, Rayner BL. Clinicopathological insights into lupus nephritis in South Africans: a study of 251 patients. Lupus. 2012; 21(9):10171024.

[11] Ismail, M. I., Fouad, M. \&Abdelhai, A. R. Clinical, laboratory, histopathology characteristics and correlations of lupus nephritis patients-A single center experience. Int J Of Adv Res. 2016; 4(1): 1338-1348.

[12] Merza RR, Ali OA, Khan HAEK. The clinicopathological study of lupus nephritis. Cukurova Medical Journal. 2014; 39.

[13] Kaur A, Calton N, Issacs R, Pawar B. Clinicopathologic correlation of patients with lupus nephritis. 2017; 3(3):6876.

[14] Shobha V, Prakash R, Arvind P, Tarey SD. Histopathology of lupus nephritis: A single-center, cross-sectional study from Karnataka, India. Int J Rheumatol Clin Immunol. 2014; 2(1):OA3.

[15] Al-Zahrani IH, QayyumA.Lupus nephritis.Clinicopathological correlation. Saudi Med J. 2007; 28(10):1503-1505.

[16] Baqui MN, Akhter S, Kabir E, Islam MS. A clinicopathological study on lupus nephritis; experience of 34 cases from Bangladesh. J Nephropharmacol. 2015; 5(1):19-23.

[17] Nezhad ST, Sepaskhah R. Correlation of clinical and pathological findings in patients with lupus nephritis: a fiveyear experience in Iran. Saudi J Kidney Dis Transpl. 2008; 19(1):32-40.

[18] Satirapoj B, Tasanavipas P, Supasyndh O. Clinicopathological correlation in Asian patients with biopsy-proven lupus nephritis. Int J Nephrol. 2015; 1-6. 